\title{
KESALAHAN PENGGUNAAN KONJUNGSI PADA MAKALAH MAHASISWA PROGRAM STUDI PENDIDIKAN BAHASA DAN SASTRA INDONESIA STKIP PGRI SUMATERA BARAT
}

\author{
Ilda Julianti, Ria Satini, Risa Yulisna \\ Program Studi Pendidikan Bahasa dan Sastra Indonesia STKIP PGRI Sumatera Barat \\ Ilda@gmail.com
}

\begin{abstract}
The backgroundof this research is because are still many errors of using conjunctions in the papers of student of the Indonesia Language and Literature education study program STKIP PGRI West Sumatera. This study aims to describe the misuse of conjunctions found in the papers of students of the Indonesian Language and Literature education study program STKIP PGRI West Sumatera. This type of research is a qualitative study using descriptive methods. The data source of this research is a paper writing scientific papers and discourse analysis of studens of Indonesian Language and Literature education study programs STKIP PGRI West Sumatera. The data in this study are errors using conjunctions in student papers. The results of data analisysis showed that in the papers written by students there were still many errors in their use. Errors of use of conjunctions obtained as many as four errors of use of conjunctions namely Pertema. Misuse of conjunctions and those placed at the beginning of sentences and excessive use of conjunctions and expressions are found in sentences. Secondly, errors in the use of conjunctions and those used at the beginning of a sentence and are not used to connect two languages in a sentence. Third, the use of conjunction errors students put the conjunction at the beginning of a sentence and is not used to connect the power between sentences. Fourth, mistakes in the use of conjunctions while those used at the beginning of a sentence, whereas this conjunction is used precisily in the middle of asentence and used to combine contradictory sentences. The most common use of conjunction errors in student papers is the use of conjunctions whereas, because many students use conjunctions while not in place ther efore the use of conjunctions used by students is declared wrong.
\end{abstract}

Keywords: Error, Usage, Conjunction.

PENDAHULUAN

Bahasa sebagai alat yang
mencerminkan kepribadian
seseorang, menjadikan bahasa yang
diperlukan dalam kegiatan sehari-
hari.Ataupun menuliskan sebuah
tulisan dalam bentuk makalah.

Komunikasi yang terjalin
karena adanya bahasa lisan maupun
tulisan menurut seseorang dapat
menggunakan sebuah konjungsi (kata
penghubung) dalam berkomunikasi
ataupun menuliskan sebuah tulisan
dalam bentuk makalah.


Bahasa tidak hanya dalam konjungsi (kata hubung) yang bentuk lisan tetapi juga dalam bentuk terdapat pada bagian kalimat dalam tulisan, dalam bentuk tulisan berupa paragraf.

makalah. Makalah membahas suatu permasalahan yang terjadi secara sistematis dan dapat melatih keterampilan menulis. Penulisan makalah disini merupakan suatu syarat dalam proses perkuliahan baik berupa tugas individu maupun kelompok.

Sebuah tulisan dalam bentuk makalah merupakan karya tulis yang dibuat oleh mahasiswa. Apabila tempat konjungsi dalam kalimat tidak tepat maka kalimat menjadi tidak efektif. Suatu kalimat dinyatakan efektif apabila struktur penyusunan kalimatnya benar. Tepat atau tidaknya penggunaan konjungsi dapat dilihat dari kalimat-kalimat dan paragrafparagraf yang tersusun rapi dalam sebuah makalah. Pembuatan makalah banyak ditemukan kesalahan penggunaan konjungsi (kata hubung) pada makalah mahasiswa Program Studi Pendidikan Bahasa dan Sastra Indonesia STKIP PGRI Sumatera Barat. Salah satunya pada makalah mata kuliah karya ilmiah dan analisis wacana. Kesalahan penggunaan Berdasarkan latar belakang di atas, tujuan penelitian ini mendeskripsikan Kesalahan Penggunaan Konjungsi Koordinatif.

Menurut Rahardi (2009:14) konjungsi merupakan kata yang memiliki fungsi yang menghubungkan dua satuan kebahasaan yang memang sejajar atau sedejarat. Selanjutnya, menurut Lubis, (2011:42) konjungsi adalah alat yang lain untuk menghubungkan sebuah kalimat dengan kalimat lain.

Menurut Rahardi (2009:14) konjungsi terbagi atas empat bagian yaitu sebagai berikut. Yaitu konjungsi coordinator kata hubungan yang bertugas hubungkan 2 unsur kebahasaan/lebih cenderung mirip tataran atau tingkat pentingnya. Konjungsi korelatif bertugas hubungkan 2 kata, dua frasa, 2 klausa yang memiliki status sintaksis atau status kalimat yang sama. Konjungsi subordinatif penghubung yang menghubungkan anak kalimat dan induk kalimat. Konjungsi antar kalimat kata penghubung ide atau 
atau gagasan pada kalimat yang satu dengan ide atau gagasan pada kalimat yang lainnya.

Menurut Wibowo (2012:65), konjungsi koordinatif adalah konjungsi ini berpotensi menggabungkan dua unsur atau lebih. Tiap-tiap unsur itu (baik berupa kata, frasa, klausa, maupun kalimat) bisa berkedudukan setara bisa juga tidak. Kemudian, menurut Alwi, (2000:65), konjungsi koordinatif adalah menggabungkan dua klausa atau lebih yang masing-masingnya mempunyai kedudukan yang setara dalam struktur konstituen kalimat.

Menurut Gani (2011:19), makalah merupakan suatu karya tulis ilmiah yang membahas suatu permasalahan secara tuntas. Biasanya penulisan makalah dimaksudkan untuk memenuhi tujuan-tujuan tertentu. Berdasarkan sasaran akhir dari penulisan makalah ini.

\section{METODE PENELITIAN}

Jenis penelitian ini adalah penelitian kualitatif yang bertujuan untuk memahami fenomena sosial termasuk fenomena yang tengah diteliti (Sugiyono, 2014:114).
Metode yang dipakai pada penelitian ini yaitu metode deskriptif.

Data pada penelitian kualitatif dapat diartikan sebagai data yang berbentuk kategorisasi, karakteristik berwujud pertanyaan atau kata-kata (Martono,2015:64). Data yang dibutuhkan pada teliti ini berupa kutipan salah gunakan konjungsi yang terdapat dalam makalah mahasiswa. Asal data pada teliti ini yaitu artikel mahasiswa STKIP PGRI Sumatera Barat.

Cara kumpul data pada teliti ini dipakai cara, yaitu pertama, mengumpulkan makalah menulis karya ilmiah dan analisis wacana dari mahasiswa setelah proses perkuliahan selesai. Kedua, setelah menggumpulkan makalah menulis karya ilmiah dan analisis wacana kemudian makalah tersebut dibaca. Ketiga, setelah dibaca seluruh makalah menulis karya ilmiah dan analisis wacana baru ditemukan kesalahan konjungsi koordinatif. Keempat, mencatat kesalahan penggunaan konjungsi koordinatif yang terdapat pada makalah menulis karya ilmiah dan analisis wacana mahasiswa tersebut. 


\section{HASIL DAN PEMBAHASAN}

Berdasarkan pendataan dari data yang di peroleh dengan jumlah data 60 data yang terdiri dari konjungsi koordinatif. Adapun data yang di dapat yaitu kesalahan penggunaan konjungsi dan terdapat 24 data, konjungsi serta 1 data, konjungsi atau terdapat 5 data, konjungsi melainkan terdapat 1 data, dan konjungsi sedangkan 29 data. Adapun bentuk kesalahan penggunaan konjungsi teramat banyak ditemukan ialah pakai konjungsi sedangkan. Salah gunakan konjungsi sedangkan yang ditemui pada makalah mahasiswa, karena dapat penggunaan konjungsi sedangkan penempatanya tidak tepat.

1. Kesalahan Penggunaan Konjungsi dan pada Makalah mahasiswa Program B.I STKIP PGRI Sumbar.

Konjungsi, merupakan salah satu bagian dari konjungsi koordinatif. Salah satu bagian dari konjungsi koordinatif adalah penggunaan konjungsi dan. Konjungsi dan berguna nyatakan gabung biasa diantara 2 buah kata sifat yang enggak bisa ditentang. Namun pada makalah mahasiswa jurusan Bahasa dan Sastra Indonesia ditemukan beberapa kesalahan penggunaan konjungsi dan, bisadilihatdibawahini.

\section{Data: 5W.Y (Makalah Analisis Wacana)}

"Puji syukur penyusun kirimkan atas khadirat tuhan yang maha esa karena dengan rahmat, karunia, serta taufik dan hidayah-Nya penyusun dapat menyelesaikan makalah tentang "konteks dan analisi wacana ragam nonsastra" ini dengan baik meskipun banyak kekurangan didalamnya. Dan juga penyusun berterima kasih pada ibu Risa Yulisna, M.Pd. selaku dosen pengampu mata kuliah analisis wacana"

Data nomor 6 terdapat kesalahan konjungsi yaitu pada konjungsi dan. Penggunaan konjungsi dan dikatakan salah, karena gunakan konjungsi tidak tepat, konjungsi dan tidak dapat diletakan diawal kalimat tetapi hanya bisa diletakan di tengah kalimat. Pada kalimat diatas, kata penghubung dan lebih baik dihilangkan, dan kalimat tersebut diperluas menjadi kalimat padu. Sebaiknya kalimat diatas dapat ditulis dengan menuliskan penyusun juga berterima kasih kepada ibu Risa Yulisna, M.Pd. maka dari itu konjungsi dan yang digunakan pada kalimat tersebut dinyatakan salah. 
2. Kesalahan Penggunaan Konjungsi serta pada Makalah STKIP PGRI Sumatera Barat

Konjungsi serta merupakan salah satu bagian dari konjungsi koordinatif. Konjungsi serta berguna untuk menyatakan gabungan biasa diantara dua buah kata sifat yang tidak bertentangan. Namuan dalam makalah mahasiswa jurusan Bahasa dan Sastra Indonesia ditemukan beberapa kesalahan penggunaan konjungsi serta, bisa dilihat dibawah ini.

\section{Data:46 Y.A (Menulis Karya Ilmiah)}

"Sehingga dalam penyusunannya tidak dilakukan secara mandiri oleh mahasiswa melainkan dengan bimbingan dari dosen pembimbing. serta sistematika penulisan skripsi pun dari suatu universitas dengan universitas lainnya dapat berbedabeda".

Pada kutipanomor 47 terdapat kesalahan penggunaan konjungsi yaitu penggunaan konjungsi serta. Pada kalimat diatas, kata penghubung serta lebih baik dihilangkan, dan kalimat tersebut diperluas menjadi kalimat padu, seperti kalaimat susunan tulisan skripsi suatu universitas dengan universitas yang lain dapat tidak sama. Pada kutipan tersebut konjungsi serta digunakan pada awal kalimat. Seharusnya penggunaan konjungsi serta digunakan ditengah kalimat dan berfungsi sebagai kata penghubug antara dua buah kata benda. Maka dari itu penggunaan konjungsi serta yang terdapat dalam makalah mahasiswa terdapat kesalahan.

3. Kesalahan Penggunan Konjungsi Atau pada Makalah Mahasiswa Program Studi Bahasa dan Sastra Indonesia STKIP PGRI Sumatera Barat

Konjungsi atau merupakan salah satu bagian dari konjungsi koordinatif. Konjungsi atau berguna menyatakan gabungan biasa diantara 2 buah kata sifat yang tidak bertentangan. Namun, ditemukan beberapa kesalahan penggunaan konjungsi atau, dapat dilahat pada.

\section{Data: 23 F.J.I (Menulis Karya} Ilmiah)

"Fungsi dari daftar pustaka adalah untuk memberikan arah bagi para pembaca buku atau karya tulis yang ingin meneruskan kajian atau untuk melakukan pengecekan ulang terhadap karya tulis yang bersangkutan" 
Data nomor 23 terdapat kesalahan konjungsi yaitu penggunaan konjungsi atau. Konjungsi atau disini tidak menunjukan penghubung pemilihan dalam kaliamat tersebut. Tetapi menghubungkan dua unsur kebahasaan. Kalimat di atas dapat disunting menjadi fungsi dari daftar pustaka adalah untuk memberikan arah bagi para pembaca buku dan karya tulis yang ingin meneruskan kajian atau untuk pengecekan ulang terhadap karaya tulis yang bersangkutan. Kesalahan konjungsi atau terjadi karena penulis kurang teliti dalam penggunaan konjungsi atau. Agar kalimat tersebut mudah dipahami, maka penggunaan konjungsi dapat di gantikan dengan konjungsi dan. Maka dari itu penggunaan konjungsi atau terdapat dalam makalah mahasiswa terdapat kesalahan

4. Kesalahan Penggunaan Konjungsi Melainkan pada Makalah Mahasiswa Program Studi Bahasa dan Sastra Indonesi STKIP PGRI Sumatera Barat

\section{Data: 4 N.N.W (Analisis Wacana)}

"Keterkaitan dan kerapian bentuk dalam ilmu bahasa dinamakan kohesi dan koherensi. Kohesi dan koherensi mempunyai peran yaitu untuk memelihara keterkaitan antarkalimat, sehingga wacana menjadi padu, tidak hanya sekumpulan kalimat yang setiap kalimat mengandung pokok pembicaraan yang berbeda. Melainkan suatu unsur dalam teks yang harus dinyatakan konsep ikatan”

$$
\text { Penggunaan konjungsi }
$$

melainkan dia kutipan kata diatas dikatakan salah, karena konjungsi melainkan pada kutipan tersebut gunakan pertama kalimat. Kalimat diatas, kata melainkan tidak dihilangkan, tetapi tanda baca sebelum kata melainkan dihilangkan maka kalimat akan menjadi seperti kalimat terkait dan rapi bentuk ilmu bahasa namakan kohesidan koherensi, dengan peran untuk pelihara terkait antara kalmiat hingga wancana jadi padu, tiap kalmiat kandung pokok bicara tidak sama, lainkan suatu unsur dalam teks dalam teks yang harus nyatakan konsep ikatan.

Seharusnya penggunaan konjungsi melainkan diletakan di tengah-tengah kalimat. Maka dari itu penggunaan konjungsi melainkan dalam makalah mahasiswa terdapat kesalahan. 
5. Kesalahan Penggunaan Konjungsi Sedangkan pada Makalah Mahasiswa Program Studi Pendidikan Bahasa dan Sastra Indonesia STKIP PGRI Sumatera Barat

Salah satu bagian dari konjungsi koordinatif adalah penggunaan konjungsi sedangkan. Namun, ditemukan beberapa kesalahan penggunaan konjungsi sedangkan, dapat dilihat pada :

\section{"Data: 1Y.M (Analisis Wacana)}

"Wacana terdiri dari wacana lisan dan tulisan, wacana lisan yaitu yang disampaikan secara langsung oleh penutur atau mitra tutur, dalam wacana lisan ini bisa dikatakan harus jelas apa yang disampaikan karena ia bersifat alami dan secara langsung. Sedangkan wacana tulisan yang dibuat memalui tulisan-tulisan, dan tidak bersifat langsung karena ia di tuliskan melalui ide-ide penulis.

$\begin{array}{ccrr}\text { Data } & \text { nomor } & 1 & \text { terdapat } \\ \text { kesalahan } & \text { konjungsi } & \text { yaitu } \\ \text { penggunaan } & \text { konjungsi } & \text { sedangkan. }\end{array}$

Mengapa demikian, karena konjungsi sedangkan pada kutipan tersebut sedangkan tidak dihilangkan, tetapi tanda baca sebelum kata sedangkan dihilangkan maka kalimat akan menjadi seperti kalimat wacana terdiri dari wacana lisan dan tulisan, wacana lisan yaitu yang disampaikan secara langsung oleh penutur atau mitra tutur, dalam wacana lisan inibisa dikatakan harus jelas apa yang disampaikan karena ia bersifat alami dan secara langsung sedangkan wacana tulisan yang dibuat melalui tulisan-tulisan, dan tidak bersifat langsung karena ia dituliskan melalui ide-ide penulis. Seharusnya penggunaan konjungsi sedangkan digunakan ditengah kalimat yang berfungsi untuk menggabungkan kalimat pertentangan. Jadi, konjungsi sedangkan tidak boleh diletakan pada awal kalimat. Maka dari itu, penggunaan konjungsi sedangkan yang terdapat kesalahan dalam makalah mahahasiswa terdapat kesalahan.

Salah satu bentuk penggunaan konjungsi yang terdapat adalah konjungsi koordinatif. Penggunaan konjungsi koordinatif dalam suatu makalah merupakan salah satu bentuk unsur bahasa yang bisa digunakan untuk memperjelas makna dari makalah yang ditulis oleh mahasiswa. Agar bahasa tersebut dapat dipahami dan memiliki tata bahasa yang baik, maka penggunaan konjungsi dalam makalah harus benar. 
Berdasarkan hasil penelitian, karena konjungsi sedangkan yang Maka dapat diketahui bahwa makalah terdapat pada makalah mahasiswa yang ditulis oleh mahasiswa masih banyak ditemui beberapa kesalahan penggunaannya. Gunakan konjungsi salah ialah gunakan konjungsi koordinatif, seperti gunakan tersebut. konjungsi sedangkan digunakan ditengah dan berfungsi untuk menggabungkan kalimat pertentangan.

konjungsi dan, atau, serta, melainkan dan sedangkan. Kesalahan gunakan konjungsi yang paling sering ditemukan yaitu penggunaaan konjungsi yang diletakkan di awal kalimat. Penggunaan konjungsi koordinatif pada umumnya tidak boleh diletakkan diawal kalimat, tetapi hanya diletakan ditengah kalimat karena konjungsi koordinatif fungsi buat hubungkan 2 bahasa.

Selain itu dalam makalah mahasiswa masih banyak ditemui gunakan konjungsi tidak suai fungsi seperti penggunaan konjungsi dan. yang diletakkan di awal kalimat, karena penggunaan konjungsi dan yang digunakan tidak menghubungkan dua unsur kebahasaan yang sama.

Penggunaan konjungsi banyak ditemukan salah yaitu gunakan konjungsi sedangkan. Penggunaan konjungsi sedangkan dikatakan salah,

Penelitian tentang kesalahan penggunan konjungsi telah pernah dilakukan oleh peneliti sebelumnya, yaitu teliti ini lakukan oleh Wasiah, M. (2014) dengan judul penelitian "Kesalahan penggunaan kata penghubung dalam penulisan Berita Utama Koran Banten Raya Edisi 1 April-31 May 2014 dan implikasinya terhadap pembelajaran Bahasa Indonesia". Berdasarkan teliti tentang salah gunakan kata hubung yang bisa pada berita pertama koran raya edisi 1 April- 31 May 2014 terdiri dari kesalahan penggunaan kata namun, tetapi, sedangkan, karena, dan, bahkan, padahal, dan lain-lain. Penelitian ini berbeda dengan penelitian sebelumnya. Perbedaannya terletak pada variabel dan sampel penelitian. Pada penelitian ini, variable penelitian yaitu Kesalahan Penggunaan Konjungsi pada Makalah Mahasiswa Program Studi Pendidikan Bahasa 
dan Sastra Indonesia STKIP PGRI Sumatera Barat. Kemudian sampel pada penelitian ini yaitu makalah menulis karya ilmiah dan analisis wacana mahasiswa Pendidikan Bahasa dan Sastra Indonesia STKIP PGRI Sumatera Barat.

\section{KESIMPULAN}

Berdasarkan hasil tersebut, dapat disimpulkan bahwa dalam makalah yang ditulis oleh mahasiswa masih banyak ditemui beberapa kesalahan penggunaanya konjungsi. Salah gunakan konjungsi diperoleh yaitu banyak lima salah guna konjungsi. Pertama. Salah guna konjungsi dan yang diletakan diawal kalimat dan gunaan konjungsi dan yang berlebih terdapat pada kalimat. Kedua, kesalahan guna konjungsi serta yang digunakan diawal kalimat Ketiga, kesalahan penggunaan konjungsi atau mahasiswa meletakan konjungsi diawal kalimat dan tidak digunakan untuk menghubungkan kluasa antara kalimat. Keempat, kesalahan penggunanaan konjungsi sedangkan yang digunakan diawal kalimat, padahal konjungsi ini tepatnya digunakan ditengah kalimat dan digunakan mengabungkan kalimatpertentangan. Kesalahan penggunaan konjungsi yang paling banyak ditemukan dalam makalah mahasiswa adalah penggunaan konjungsi sedangkan, karena mahasiswa banyak menggunakan konjungsi sedangkan tidak pada tempatnya, maka dari itu penggunaan konjungsi yang digunakan mahasiswa dinyatakan salah.

\section{DAFTAR PUSTAKA}

Alwi. (2000). Tata Bahasa Baku Bahasa Indonesia. Jakarta: Balai Pustaka

Gani, Erizal. (2011). Menulis Karya Ilmiah. UNPPress.

Lubis, Hamid Hasan. (2011).Analisis Wacana Pragmatik. Medan: Angkasa Bandung.

Martono, Nanang. (2015). Metode Penelitian Sosial. Jakarta: Rajawali Press.

Rahardi, Kunjana. (2009). Penyuntingan Bahasa Indonesia untukKarang-Mengarang. Yogyakarta: Erlangga.

Sugiyono. (2014). Metode Penelitian Kuantitatif, Kualitatif dan $R \& D$. Bandung: Alfabeta.

Wibowo, Wahyu. (2012). Tata Permainan Bahasa Karya Tulis Ilmiah. jakarta: PT. Bumi 
Aksara.

Wasiah, M. (2014). Kesalahan Penggunaan Kata Penghubung dalam Penulisan Berita Utama Koran Banten Raya Edisi 1 April - 31 Mei 2014 dan Implikasinya Terhadap Pembelajaran Bahasa Indonesia. Jakarta: Universitas Islam NegeriSyarif Hidayatullah 